\title{
How to create successful vasectomy programs
}

\author{
Brian Perry \\ Catherine Packer \\ Dawn S. Chin-Quee \\ Trinity Zan \\ Dominick Shattuck
}

Follow this and additional works at: https://knowledgecommons.popcouncil.org/departments_sbsr-rh How does access to this work benefit you? Let us know!

\section{Recommended Citation}

Perry, Brian, Catherine Packer, Dawn S. Chin-Quee, Trinity Zan, and Dominick Shattuck. 2016. "How to create successful vasectomy programs." Durham, NC: FHI 360 and Washington, DC: The Population Council, The Evidence Project. 


\section{HOW TO CREATE SUCCESSFUL VASECTOMY PROGRAMS}

Vasectomy is among the most costeffective and safest family planning (FP) methods for meeting the needs of men and women who desire to limit future births, however it is very underused in low-resource settings. In most areas where permanent contraceptive method use is low, couples too often depend on short-term methods (e.g. condoms, pills, injectables) for limiting future births. This is both expensive in the long-term and less effective given discontinuation and/or incorrect use. By promoting and supporting the voluntary use of vasectomy, countries can move toward their FP goals, decrease their service delivery costs and integrate men into reproductive health as both informed supporters of women-controlled methods and as contraceptive users.

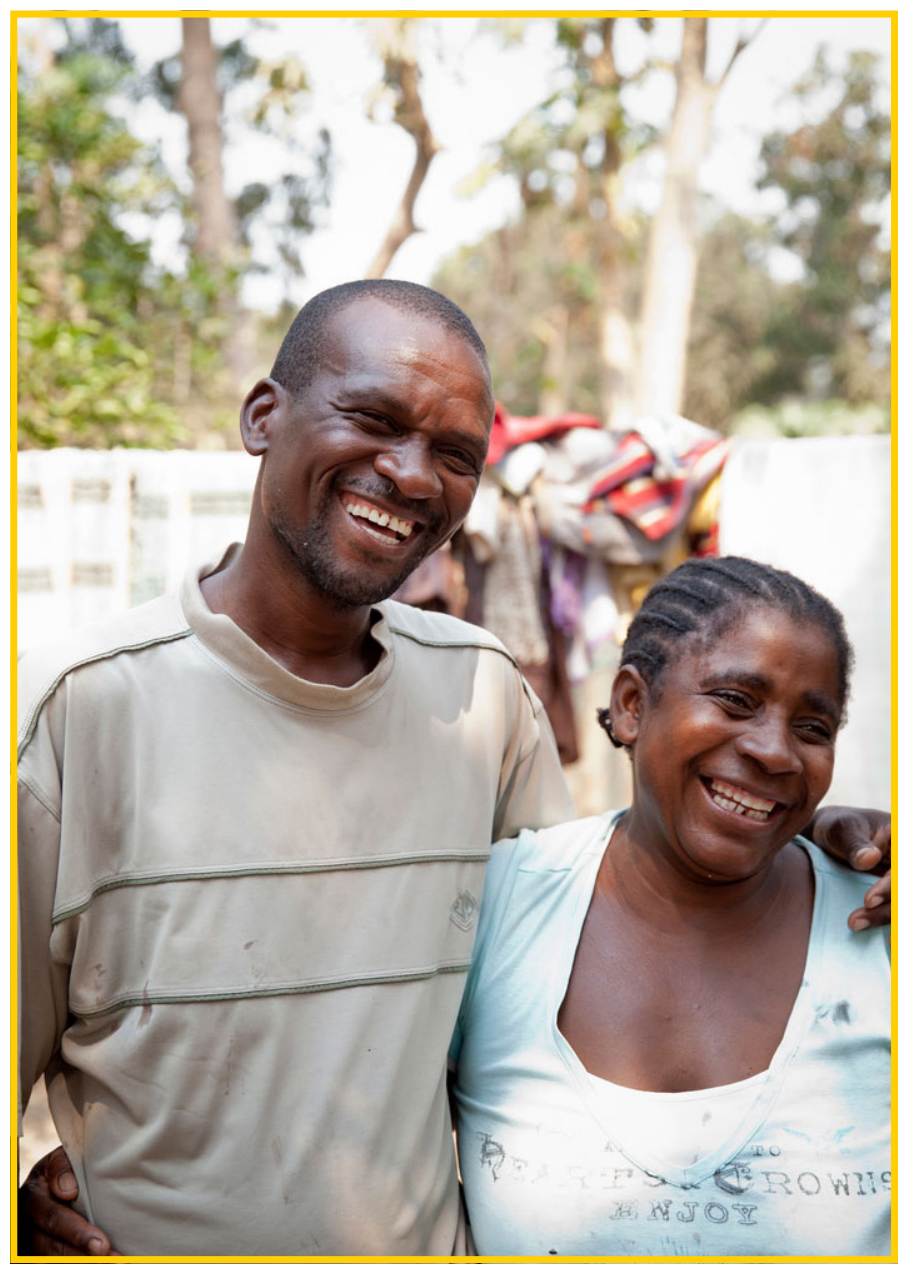

The purpose of this brief is to help advocates, program planners, policymakers and Ministries of Health establish policies, allocate resources, and advocate for successful vasectomy programs. The Supply-Enabling EnvironmentDemand (SEED) Programming Model ${ }^{\mathrm{TM}}$ has been established as a useful global framework for sexual and reproductive health programming. The following three components must be mutually reinforced in order to create and sustain successful vasectomy programs: 1) creating, increasing, and sustaining demand for vasectomy services, 2) increasing supply of vasectomy services, and 3) creating an enabling environment for vasectomy programs.

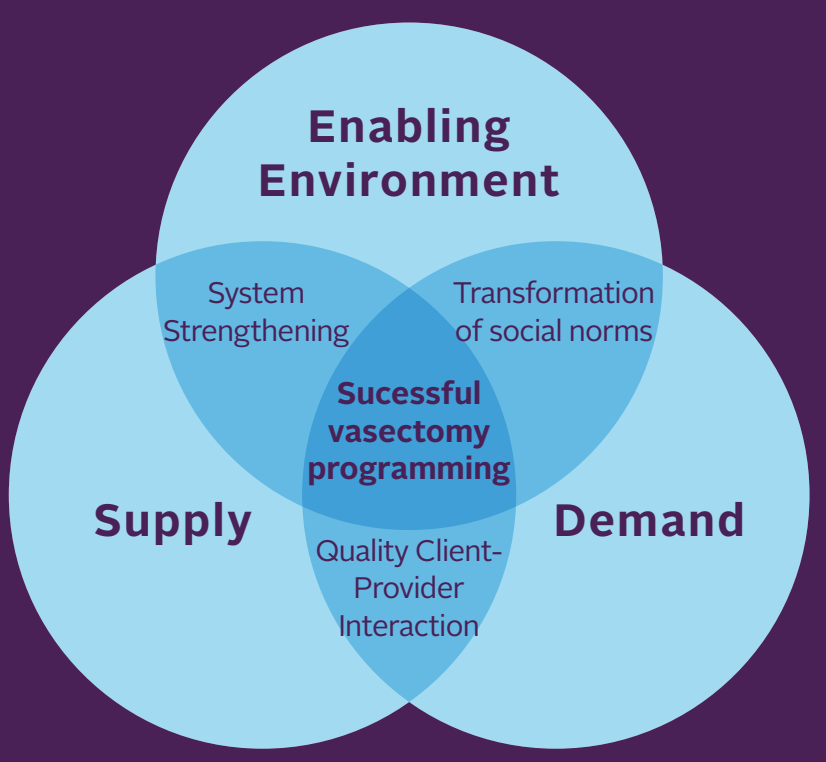

Adapted from EngenderHealth's Supply-Enabling Environment-Demand (SEED) Programming Model ${ }^{\mathrm{TM}}$ 
The recommendations below come from a recent review ${ }^{1}$ of vasectomy projects and related research.

Recommendations were synthesized to aid policymakers and program implementers to create a greater enabling environment, increase supply of and demand for vasectomy services.

\section{FOSTERING AN ENABLING ENVIRONMENT FOR VASECTOMY}

Sociocultural, economic, and policy factors influence health services and social norms related to FP in general and to vasectomy in particular. An enabling environment for vasectomy requires engagement of governments, communities, and civil societies to support and advocate for gender equitable norms, accountability, evidence-based policies and high-quality vasectomy services.

The following are recommendations for fostering an enabling environment in which men are included as current and future family planning users:

\section{POLICY LEVEL:}

- Establish supportive policies and political support for male-inclusion and a focus on couples in national FP and reproductive health plans.

- Ensure that vasectomy is included in all national FP norms, guidelines and procedures, and that barriers or restrictions to receiving vasectomy services are not enacted.

- Develop a Costed Implementation Plan for FP, which includes the expansion of vasectomy services and demand creation activities, in order to strategically invest limited resources and achieve FP commitments.

- Create a comprehensive national sexual/ reproductive health curriculum for youth that includes permanent methods in order to begin early sensitization on vasectomy as a viable way to achieve desired family size.

\section{HEALTH SYSTEM LEVEL:}

- Address concerns for cost or missing work from getting a vasectomy by making vasectomy affordable and compensating men for time missed from work, when possible.

- Identify ways to educate men about reproductive health earlier in life, preparing them to openly support their partners' FP use or to use vasectomy or condoms.

- Create "male-friendly" reproductive health services by training male health workers to counsel men about their FP options, potential side effects and the benefits of limiting and spacing children.

- Motivate providers to offer comprehensive client-centered counseling where all FP options are discussed and counseling is tailored to the individual's or couple's unique fertility goals.

\section{HOUSEHOLD/COMMUNITY LEVEL:}

- Engage satisfied vasectomy clients and couples, trusted local healthcare workers and religious and community leaders as advocates for greater male involvement in FP and use of contraception.

- Address gender-related norms that may negatively impact FP decision-making, by empowering women and couples to talk openly about their reproductive intentions.
Program highlight: Gaining the support and public endorsement of religious and community leaders and institutions can improve public attitudes towards and increase vasectomy uptake. For example, through the ACQUIRE project in Tanzania, the Heri Seventh Day Adventist Mission Hospital provided vasectomy services and educational seminars about the benefits of contraception, including vasectomy. 2,3 This hospital hosted and supported a regional center of excellence in no-scalpel vasectomy (NSV) and provided the majority of vasectomies in a six-year period in the Kigoma region. In addition, Anglican religious leaders helped disseminate information about a surgeon's mobile clinic that offered vasectomy services, which he occasionally held at a Pentecostal health clinic. 


\section{PROVIDING HIGH QUALITY VASECTOMY SERVICES}

Provision of high-quality vasectomy services must include adequate infrastructure, supplies and equipment as well as well-trained, skilled, motivated and supported staff. It is also important to have administrative, financial and management systems in place that are accountable to the communities they serve.

The following are recommendations for improving access to and quality of vasectomy service delivery:

\section{SKILLS \& KNOWLEDGE:}

- Ensure all healthcare staff, including outreach community-based workers, have adequate theoretical knowledge of vasectomy and its advantages compared to other methods.

- Train providers on highly effective vasectomy procedures (e.g. NSV with fascial interposition and thermal cautery). Trainees need supervised handson training. Trainee competency should be assessed based on trainee confidence and ability rather than on a specific number of vasectomies performed.

- Improve capacity of lab technicians to perform spermograms for post-vasectomy semen analysis.

- Improve permanent method counseling, which includes addressing misconceptions and facilitating partner communication, for individuals and couples so clients can make informed voluntary decisions about their reproductive health.

- Build local capacity for on-going vasectomy training and supportive supervision, which includes routine evaluation of service provision and quality improvement.

\section{SYSTEMS:}

- Expand access to vasectomy services and availability of trained vasectomy providers through mobile outreach and/or task shifting.

- Establish permanent methods counseling guidelines based on international standards.

- Expand and strengthen the capabilities of referral networks to inform potential clients about available services and connect them with providers.

- Improve patient follow-up by properly informing clients about the importance of post-vasectomy semen analyses and develop strategies for improving access to post-vasectomy care and follow-up, such as utilizing community health workers.

Minimize potential stockouts of essential equipment through consistent logistical and financial support.

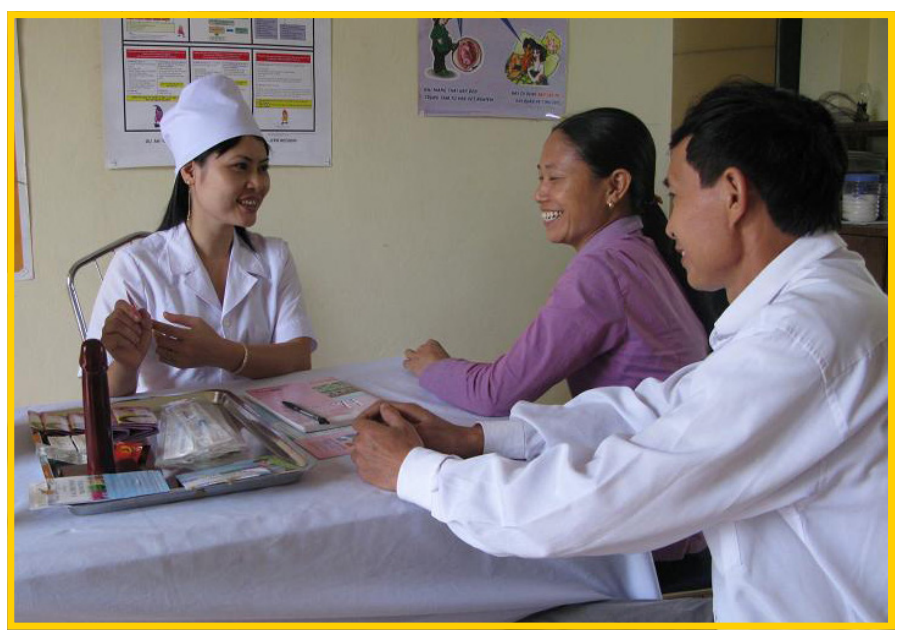

Program highlight: The Capacity Project in Rwanda trained a small cadre of physicians and nurses in the NSV procedure and provided surgical training equipment and supplies. ${ }^{4,5}$ The project then trained three of these physicians and four nurses as trainers who could then train other health teams in other facilities and supported vasectomy teams to make outreach visits from the hospital to six health centers. The physician and nurse trainers instructed seven other physicians and ten nurses at hospitals in four additional districts. This resulted in a cascade of trained providers and increased vasectomy provision at the health center level.

The Rwanda Ministry of Health, with technical assistance from the PROGRESS Project, decided to expand access to this new vasectomy technique with the goal of training at least two doctors and three nurses in each of the 43 district hospitals to provide NSV with thermal cautery and fascial interposition. Between 2010 and 2012, 2,523 vasectomies were performed by doctors trained as a result of this initiative. Vasectomy was integrated into routine mobile outreach activities that were delivered to each health center within the district hospital's catchment area, resulting in the sustained integration of vasectomy services in the health system. 


\section{GENERATING \& SUSTAINING DEMAND FOR VASECTOMY SERVICES}

In order to be motivated to use vasectomy services, an individual or couple needs accurate knowledge of and positive attitudes towards vasectomy. Potential vasectomy clients must also know where services are available, understand details about the procedure (e.g. side effects, recovery time, and time required for back-up contraception), and believe that services are confidential.

The following list outlines specific recommendations for generating and sustaining demand for vasectomy services:

\section{WHAT}

- Use formative assessments to research misconceptions and barriers to vasectomy use in specific communities.

- Improve awareness and provide accurate knowledge to men and women about vasectomy through effective information, education and communication strategies to directly address misinformation in communities.

Emphasize positive messages about vasectomy (e.g. the procedure is painless, quick recovery time, highly effective, has economic and health benefits for the family and doesn't interfere with sexual function or pleasure).
WHO

- Provide accurate information and messaging tailored to the unique and shared interests of men, women and couples.

- Provide antenatal and postpartum women and couples with accurate information about vasectomy in order to help couples plan their family size while already engaged in services related to childbirth.

\section{WHERE}

Reach men with accurate vasectomy messaging by disseminating information through workplaces and religious and education institutions.
HOW

- Use multiple popular communication media channels strategically to promote continued demand for vasectomy.

- Engage satisfied clients as "champions" to share testimonials with men and women about their experience and dispel myths and discuss benefits of receiving a vasectomy.

- Engage trusted sources in the community such as healthcare providers and religious and cultural leaders to give information to men.

It is critical that SEED components of vasectomy programs are mutually reinforced. For example, if demand dwindles, providers will not have clients and then may lose desire or confidence in their ability to perform vasectomies.

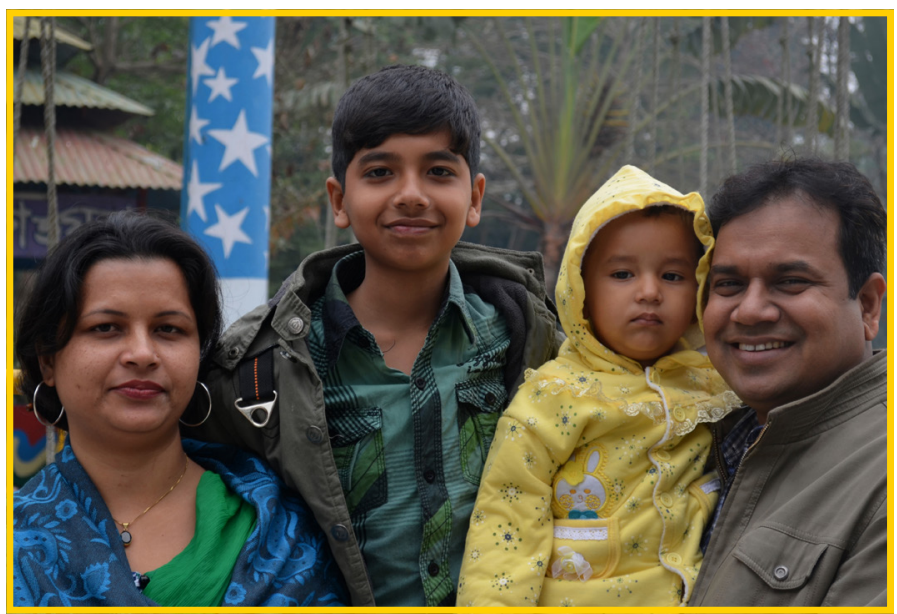

Program highlight: The ACQUIRE project's "Permanent Smile" communications campaigns increased vasectomy demand and uptake in several implementing countries. $6,7,8,9$ The goals of the campaigns were to raise awareness of and improve attitudes towards vasectomy by: dispelling myths about vasectomy; eliminating stigma toward the procedure; improving male involvement; and encouraging dialogue between potential clients and providers. For example, in Bangladesh, posters and television commercials contained the message, "My husband is best", which was highly regarded among men and women. Men liked the fact that the materials clearly illustrated their role in FP decisionmaking and the notion that a wife would value the husband's involvement, and women identified with the pride expressed by the wife in the material. While campaigns resulted in increased demand, it was not sustained beyond the campaigns in Bangladesh, Honduras and Ghana, highlighting the importance of having multiple and on-going demandgeneration activities coupled with strong supply-side components and an enabling environment. 
TOOLS AND RESOURCES:

The following tools and resources can enable program planners to advocate for, design and implement quality vasectomy programs:

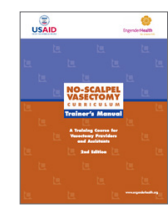

No-Scalpel Vasectomy Curriculum Trainer's Manual

www.engenderhealth. org/files/pubs/familyplanning/nsv_curric_ trainers_final.pdf

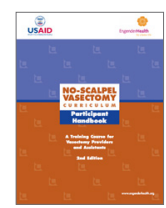

No-Scalpel Vasectomy Curriculum Participant Handbook

www.engenderhealth. org/files/pubs/familyplanning/nsv_curric_ participant_final.pdf

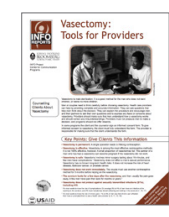

Vasectomy: Tools for providers

www.k4health. org/toolkits/infopublications/vasectomytools-providers

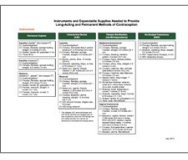

Instruments and Expendable Supplies Needed to Provide Long-Acting and Permanent Methods of Contraception

www.engenderhealth. org/files/pubs/ family-planning/lapmequipment-list.pdf

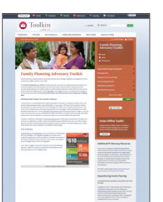

Family Planning Advocacy Toolkit

www.k4health.org/ toolkits/family-planningadvocacy

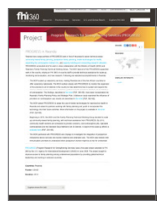

Rwanda Vasectomy Integration Program Brief

www.fhi360.org/ projects/progress-rwanda

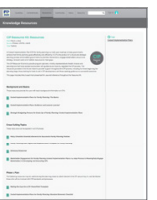

Costed Implementation Plan Resource Kit www familyplanning2020. org/resources/5982

\section{REFERENCES:}

${ }^{1}$ Perry B, Packer C, Chin Quee D, Zan T, Dulli L, and Shattuck D. Recent experience and lessons learned in vasectomy programming in low-resource settings: a document review. Durham, NC: FHI 360 and Washington, DC: The Population Council, the Evidence Project. 2016.

${ }^{2}$ Bunce A, Guest G, Searing H, Frajzyngier V, Riwa P, Kanama J, et al. Factors affecting vasectomy acceptability in Tanzania. International Family Planning Perspectives. 2007;33(1):13-21.

${ }^{3}$ Frajzyngier V, Bunce A, Lusiola G, Searing H, Riwa P. Factors affecting vasectomy acceptability in the Kigoma region of Tanzania: New York, New York, EngenderHealth, ACQUIRE Project, 2006.
${ }^{4}$ de Vries DH, Wilson A, Murphy C, Davis J. Repositioning family planning: Rwanda's no-scalpel vasectomy program: Chapel Hill, North Carolina, IntraHealth International, Capacity Project, 2009

${ }^{5}$ Davis J, de Vries DH, Sinzahera J, Twahirwa W, Sokal DC. Final feasibility evaluation for no-scalpel vasectomy in Rwanda: Chapel Hill, North Carolina, IntraHealth International, Capacity Project, 2009

${ }^{6}$ Taylor J. Revitalizing underutilized family planning methods. Using communications and community engagement to stimulate demand for vasectomy in Honduras. 2008.
${ }^{7}$ Taylor J. Revitalizing underutilized family planning methods. Using communications and community engagement to stimulate demand for vasectomy in Bangladesh: New York, New York, EngenderHealth, ACQUIRE Project, 2008

${ }^{8}$ Rajani N. 'Get a Permanent Smile' -increasing awareness of, access to, and utilization of vasectomy services in Ghana: New York, New York, EngenderHealth, ACQUIRE Project, 2006.

${ }^{9}$ Cisek C, Taylor J. Revitalizing underutilized family planning methods. Assessing the impact of an integrated supply-demand vasectomy initiative in Ghana: New York, New York, EngenderHealth, ACQUIRE Project, 2008

\section{PHOTO CITATIONS}

\section{Photo 1}

A smiling couple.

(c) Jessica Scranton/FHI 360
Photo 2 - ID: 37321-76

A health staff member provides counseling services on family planning to a couple at a commune health station in Xuan Duc, My Hao, Hung Yen, Vietnam.
Photo 3 - ID: 2009-29

A family in Bangladesh.

(C) 2014 Asad Rassel, Courtesy of Photoshare 


\section{THE EVIDENCE PROJECT}

POPULATION COUNCIL

4301 Connecticut Avenue, NW, Suite 280

Washington, DC 20008 USA

Tel +1202 2379400

Evidenceproject.popcouncil.org

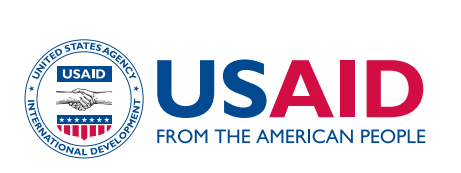

Evidence

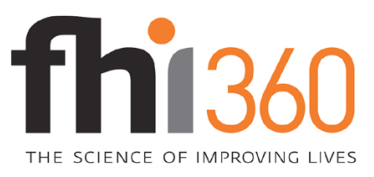

This work is made possible by the generous support of the American people through the United States Agency for International Development (USAID) under the terms of The Evidence Project, co-operative agreement no. AID-OAA-A-13-00087. The findings and conclusions are the sole responsibility of the authors and do not necessarily reflect the views of USAID or the United States Government.

The Evidence Project seeks to expand access to high quality family planning/ reproductive health services worldwide through implementation science, including the strategic generation, translation, and use of new and existing evidence. The project is led by the Population Council in partnership with the INDEPTH Network, the International Planned Parenthood Federation, PATH, and the Population Reference Bureau.

FHI 360 is a nonprofit human development organization dedicated to improving lives in lasting ways by advancing integrated, locally driven solutions. Our staff includes experts in health, education, nutrition, environment, economic development, civil society, gender, youth, research and technology - creating a unique mix of capabilities to address today's interrelated development challenges. FHI 360 serves more than 60 countries, all 50 U.S. states and all U.S. territories.

For more information about vasectomy programmatic recommendations, contact:

FHI 360

Mailing address:

359 Blackwell Street,

Suite 200, Durham, NC 27701

Telephone: +19195447040

Fax: +1 9195447261

Published in March 2016

\section{Suggested Citation:}

Packer C, Perry B, Chin-Quee D, Zan T, and Shattuck D. How to create successful vasectomy programs.

Durham, NC: FHI 360 and Washington, DC: The Population Council, the Evidence Project. 2016.

Copyright (c) 2016 FHI 360. All rights reserved. 